\title{
The hemodynamic approach to evaluating adolescent varicocele
}

\author{
Marcello Cimador, Marco Castagnetti, Ignazio Gattuccio, Marco Pensabene, Maria Sergio \\ and Enrico DeGrazia
}

\begin{abstract}
During adolescence, the risk of developing a varicocele increases. Prevalence is less than $1 \%$ in boys aged younger than 10 years, but approaches that of the general adult population (about 15\%) during puberty. For adolescent males with varicoceles, surgical risk factors have not yet been clearly delineated and clinical severity correlates poorly with prognosis. Fortunately, the widespread use of Doppler ultrasonography is transforming the diagnostic work-up for this demographic. A continuous reflux detected by color Doppler ultrasound (CDUS) is thought to have a negative prognostic value and evidence suggests that a peak retrograde flow above $38 \mathrm{~cm}$ per second is a powerful predictor of lack of spontaneous improvement in adolescent patients with $\geq 20 \%$ asymmetry between testes. CDUS also enables the detection of varicocele resulting from reflux in the deferential vein adjunctive to a refluxing internal spermatic vein; a causality that accounts for approximately $15 \%$ of cases. In addition to a diagnostic role, hemodynamic parameters can be used to predict the risk of persistence or worsening asymmetry. Although further studies are necessary to validate single parameters, it seems that the more severe the reflux, the greater the likelihood that the patient will develop testicular asymmetry.
\end{abstract}

Cimador, M. et al. Nat. Rev. Urol. advance online publication 27 March 2012; doi:10.1038/nrurol.2012.41

\section{Introduction}

A varicocele is a palpable dilation in the pampiniform plexus-a complex network of veins just above the testicle-secondary to the retrograde flow of blood to the testicle (Figure 1). Distally, these veins divide themselves into three major systems; the internal spermatic vein (ISV), the external spermatic vein, and the deferential vein (Figure 2). About $90 \%$ of varicoceles occur on the left side. ${ }^{1}$ The specific anatomy of the ISV on the left side results in a predisposition to valve insufficiency and the majority (about 75\%) of varicocele are caused by a reflux in this vein. Coolsaet ${ }^{2}$ classified this variant of varicocele as type 1 . Coolsaet type 2 varicoceles are caused by a reflux into the iliac venous system (either the cremasteric vein or the deferential vein) and Coolsaet type 3 varicoceles are the result of a reflux in both the iliac and renospermatic venous systems. ${ }^{2}$

Our current knowledge regarding the vascular anatomy of varicocele is largely based on venographic studies. These studies have highlighted the rigidity of the Coolsaet classification system and shown that, in a proportion of cases, there might also be refluxing pelvic collaterals, which are not considered in the current system. ${ }^{2-4}$ Furthermore, venographic evidence has challenged the existence of cremasteric reflux. ${ }^{5}$ Although venography has provided us with important insights into the functional anatomy of varicocele, it is an invasive investigation and its widespread use does not seem warranted in adolescent patients.

Competing interests

The authors declare no competing interests.
Color Doppler ultrasonography (CDUS) is a noninvasive alternative to venography. It enables assessment of the functional anatomy subtending the varicocele $e^{6-8}$ and provides a comprehensive evaluation of the three major venous networks draining the pampiniform plexus - the ISV, the cremasteric veins, and the deferential veins-distinguishing refluxing collateral and differentiating refluxing veins from veins dilated due to overflow. ${ }^{9}$ In a recent study of 148 adolescent and pediatric patients, CDUS identified reflux in the ISV alone in 126 patients $(85.1 \%)$, reflux in both the ISV and the deferential vein in 21 patients $(14.1 \%)$, and an isolated deferential reflux in one patient $(0.6 \%) .{ }^{8}$ Consistent with previous study findings, none of the patients presented with a cremasteric reflux. ${ }^{5}$

Aside from a role for CDUS in evaluating the functional anatomy of varicoceles and the surrounding venous networks, this imaging approach has several additional roles in the assessment and surgical treatment of patients with varicocele. The main parameters that can be assessed using this tool are testicular volume, the diameters of the veins forming the varicocele, and the hemodynamic severity of the reflux. CDUS can also be used to detect subclinical varicoceles and assess patient suitability for surgical therapy. ${ }^{6}$ In this Review, we summarize the available evidence that specifically relates to clinical decision making when managing an adolescent patient with varicocele. Data in adults are also discussed so that treatment recommendations for these two groups of patients can be compared. We discuss the role of CDUS at various stages of clinical
Section of Pediatric

Urology, Pediatric

Surgery Unit,

Department for Mother

$\&$ Child Care and

Urology, University of

Palermo, Via Alfonso

Giordano 3, 90100

Palermo, Italy

(M. Cimador,

I. Gattuccio,

M. Pensabene,

M. Sergio, E. DeGrazia).

Section of Pediatric

Urology, Urology Unit,

Department of

Oncological and

Surgical Sciences,

University Hospital of

Padua, Via

Giustiniani 2, 35128

Padua, Italy

(M. Castagnetti).

Correspondence to:

M. Cimador

marcello.cimador@

unipa.it 


\section{Key points}

- For adolescent patients with varicocele, clinical severity correlates poorly with prognosis and is inadequate for selecting candidates for varicocelectomy

- Unlike in adults, the diameter of the dilated veins of the pampiniform plexus has poor diagnostic and prognostic value in adolescents

- A continuous reflux might have a negative prognostic value in adolescents with varicocele

- A peak of retrograde flow above $38 \mathrm{~cm}$ per second might be a powerful predictor of lack of spontaneous improvement in adolescent patients with varicocele and $\geq 20 \%$ asymmetry between testes

- Doppler ultrasonography might enable the detection of cases in which varicocele is due to a reflux in the deferential vein in adjunct to a refluxing internal spermatic vein management-including clinical grading, diagnostic evaluation, surgical therapy, and postoperative followup-with a particular focus on the clinical importance of hemodynamic parameters obtained by preoperative and follow-up CDUS.

\section{Clinical assessment \\ Testicular size and symmetry}

Testicular growth arrest, ipsilateral to the varicocele, can be considered the hallmark of testicular damage in adolescent varicocele. ${ }^{10} \mathrm{~A}$ strong correlation exists between reduced testicular size and abnormal semen parameters. ${ }^{11}$ Semen analysis of 57 adolescent patients aged $14-20$ years revealed that $\geq 10 \%$ testicular asymmetry was associated with a significantly reduced sperm concentration and total motile sperm count. Reductions in sperm motility were even more significant in patients with $>20 \%$ asymmetry. There is some discrepancy regarding the threshold values for testicular size that indicate clinically relevant asymmetry, but typical threshold values used are $10 \%$, $15 \%$, and $20 \%$, or a volume difference of $2-3 \mathrm{~cm}^{3} .{ }^{12-15}$

The two most commonly used methods for assessing testicular size and asymmetry are by comparison with an orchidometer and by ultrasonography. The orchidometer has the advantage of being quick and inexpensive, but lacks accuracy compared to ultrasonography. Overall, studies in adults have shown an impressive correlation between measurements obtained using these two instruments in the hands of an experienced clinician, ${ }^{16}$ but both approaches are prone to an increased risk of overestimating testicular size for patients with small testicles. ${ }^{17}$ This issue is particularly pertinent in the case of adolescent patients, for whom a significant proportional difference between testicular volumes may correspond to a difference of just a few millimeters in the diameter of each testicle. The use of low standardized threshold values, such as $\geq 10 \%$, to define significant asymmetry causes further problems in this group of patients. Thus, it has been proposed that the clinical management of an adolescent with varicocele should include an annual assessment of the testicular volumes using ultrasonography..$^{18}$ When interpreting CDUS results, it is worth noting that the formula 'volume $=0.71 \times$ length $\times$ width $\times$ height' is more accurate for calculating the volume of the testicular ellipsoid than the previously used formula 'volume $=0.52 \times$ length $\times$ width $\times$ height. ${ }^{19}$

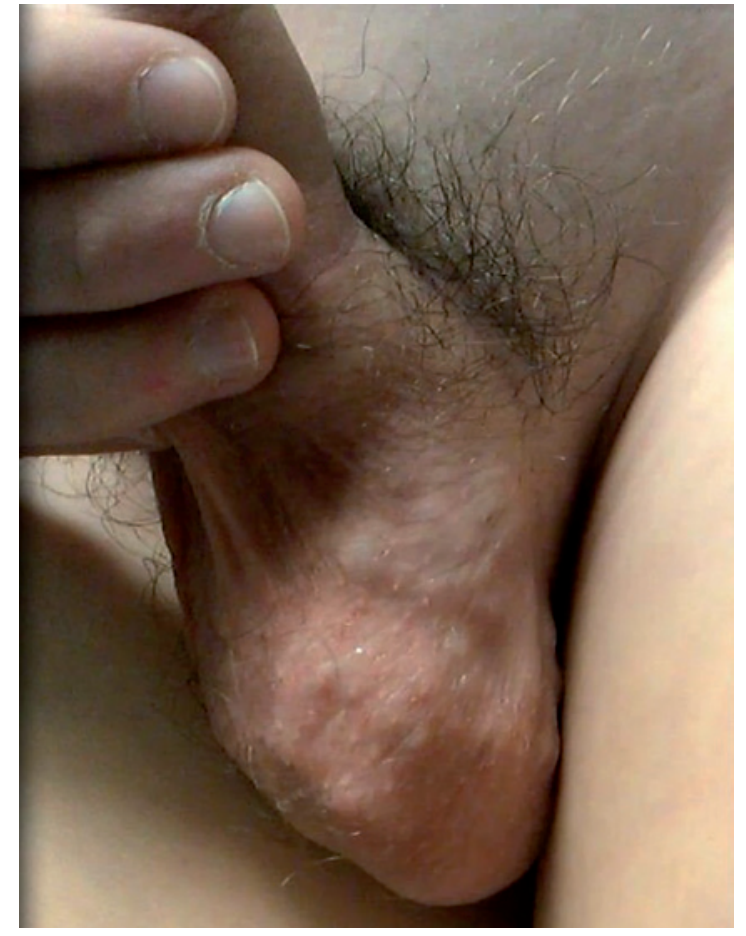

Figure 1 | An example of a Dubin-Amelar grade 3 varicocele. The patient in question is a 13-year-old adolescent with evident dilatation of the upper scrotal veins.

\section{Clinical grading}

The clinical grading system most commonly used to assess varicocele severity was originally proposed by Dubin and Amelar ${ }^{1}$ and differentiates three grades of varicocele (Table 1); grade I (only detectable during a Valsalva maneuver), grade II (palpable), and grade III (visible). This grading system was later expanded by the WHO to include grade 0 or 'subclinical' varicocele, which is absent upon physical examination (both at rest and during the Valsalva maneuver) and can only be detected by thermography or CDUS. ${ }^{20}$

In adolescents, the relationship between clinical grade of varicocele and testicular asymmetry is unclear. In a study involving 124 boys aged 7-18 years, asymmetry was observed in $39 \%$ of patients with grade II varicocele and $56 \%$ of patients with grade III varicocele $(P<0.01)$, indicating a potential correlation between grade and asymmetry. ${ }^{21}$ However, a mid-adolescence growth arrest, reported in approximately $25 \%$ of patients with testes of equal size at diagnosis, was shown to occur independently of varicocele grade. Following on from these initial observations, increasing evidence now suggests that a correlation between varicocele size and testicular damage is questionable for this patient demographic. In a more recent study involving 168 patients aged 8-21 years, no significant difference in testicular disproportion (mean volume differential) was established between the three Dubin and Amelar varicocele grades $(P=0.10)$. Similarly, no significant correlation was identified between varicocele and volume differential when patients were categorized into three levels of volume differential $(<10 \%, 10-20 \%,>20 \% ; P=0.48) .{ }^{22}$ Overall, 
clinical severity has been shown to correlate poorly with prognosis in adolescents and clinical grading systems that are currently used to assess adults for surgical suitability are often inappropriate for younger patients.

\section{Vein diameter}

An important issue regarding the assessment of vein diameter is measurement standardization. Some clinical researchers recommend measuring vein diameter at the lower pole, ${ }^{23}$ but the most commonly used measurement is maximum vein diameter (MVD) of the pampiniform plexus, assessed during the Valsalva maneuver with the patient in the supine position. ${ }^{24,25}$ Multiple measurements of the same vessel (typically $\geq 3$ ) are recommended to ensure consistency. ${ }^{25}$

In adults, vein diameter has been shown to correlate with the presence of reflux in the vein, although proposed threshold values vary. A threshold value of $3 \mathrm{~mm}$ has been suggested by one research group, on the basis that only $62.3 \%$ of patients with an MVD below this value had a venous reflux, compared to $94.4 \%$ of patients with an MVD above this value. ${ }^{25}$ Other researchers have proposed different threshold values based upon observations that, in a study of 156 testicles, all veins with an MVD of greater than $3.5 \mathrm{~mm}$ demonstrated reflux, whereas only one case of reflux was established in veins with an MVD of less than $2.5 \mathrm{~mm}$, and $65 \%$ of veins with a MVD of $2.5-3.5 \mathrm{~mm}$ exhibited reflux. ${ }^{26} \mathrm{In}$ another study of 270 adult men, varicocele diagnosis was dependent upon an MVD of at least $2.45 \mathrm{~mm}$ at rest (sensitivity $=84 \%$; specificity $=81 \%$ ) or $2.95 \mathrm{~mm}$ during the Valsalva maneuver (sensitivity $=84 \%$; specificity $=84 \%) .{ }^{27}$ However, there is also evidence to suggest that reflux can occur in veins smaller than $2 \mathrm{~mm}$ in diameter. ${ }^{28}$

In addition to its diagnostic role, MVD also has a prognostic role in adults. ${ }^{29}$ Increased testicular venous size has been associated with an improvement in semen analysis parameters following varicocele repair. ${ }^{30}$ Median sperm count and motility improved by $210 \%$ and $53 \%$, respectively, following varicocelectomy in men with an MVD of more than $3 \mathrm{~mm}$. In another report, postvaricocelectomy improvements in sperm concentration, motility, and morphology were all shown to be more pronounced in patients with a testicular MVD of $>2.5 \mathrm{~mm}$ than in patients with a MVD of $<2.5 \mathrm{~mm} .^{23}$

In adolescents, the clinical utility of vein diameter measurement has not yet been fully established. For this reason, diagnoses based on vessel diameter alone are likely to be characterized by a high number of false positives and negatives ${ }^{31}$ By comparison to adult anatomy, even relatively small varicoceles associated with veins with small diameters are easily palpable in the smaller scrotums of adolescents. In one study, ${ }^{24}$ the majority of adolescent patients with a palpable and visible varicocele had an MVD of less than $2.6 \mathrm{~mm}$. Interestingly, the same research group also noted a positive correlation between increases in MVD and Tanner stage. A dilated vein does not, however, necessarily correspond to reflux and, overall, it appears that MVD has a very limited

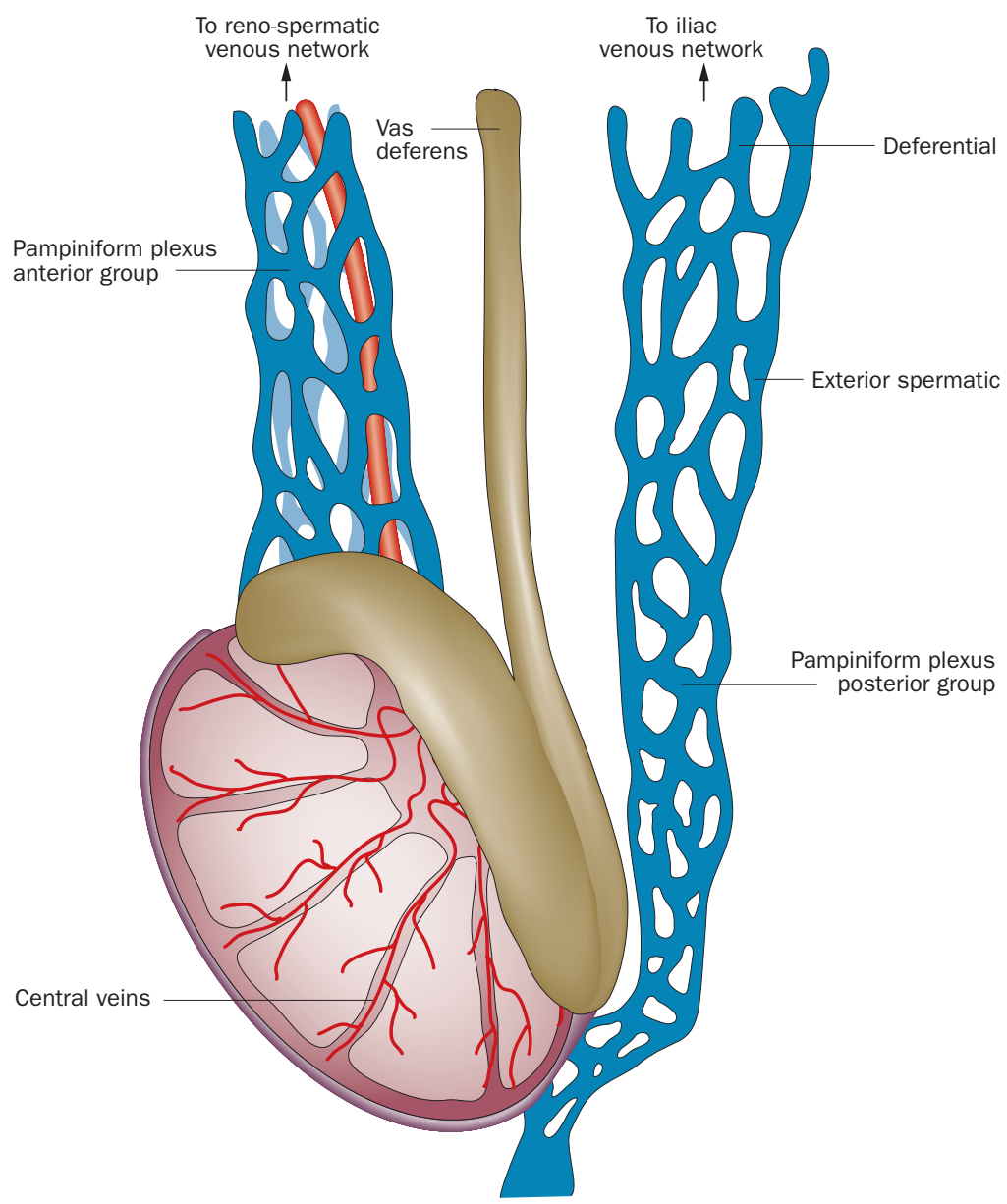

Figure 2 | Deep venous circulation of the testes. The internal spermatic vein drains the anterior plexus. The posterior plexus is linked to the iliac vessels via the deferential and exterior spermatic (or cremasteric) veins.

diagnostic value in children and adolescents. In terms of predicting prognosis in adolescent patients, a correlation between MDV and testicular damage is also questionable. ${ }^{24}$ Although evidence suggests that MVD is not an accurate or reliable predictor of progression of testicular asymmetry, ${ }^{17}$ a significant linear negative relationship exists between MVD and sperm motility in patients aged $17-19$ years with left-sided varicocele. ${ }^{32}$

\section{Hemodynamic assessment}

The use of ultrasonography in varicocele assessment has been extensively accepted in clinical urological practice and the European Association of Urology (EAU) 2011 guidelines included recommendations regarding the use of Doppler color flow mapping for diagnosing venous reflux and subclinical varicocele, and assessing testicular size in order to detect hypoplasia. ${ }^{33}$ The use of hemodynamic parameters, on the other hand, has not yet been corroborated by prospective randomized studies or introduced into guidelines for pediatric and adolescent patients. Nonetheless, in clinical practice, hemodynamic classification can help to better define varicocele and identify surgical candidates. In this context, the widespread use of these parameters by an increasing number 


\begin{tabular}{|c|c|c|c|c|c|c|}
\hline Grade & 0 & 1 & 2 & 3 & 4 & 5 \\
\hline \multicolumn{7}{|c|}{ Clinical grades } \\
\hline WHO & $\begin{array}{l}\text { Detected only with } \\
\text { thermography or } \\
\text { ultrasound }\end{array}$ & $\begin{array}{l}\text { Visible or palpable } \\
\text { during Valsalva } \\
\text { maneuver }\end{array}$ & Palpable but not visible & $\begin{array}{l}\text { Easily palpable and } \\
\text { visible }\end{array}$ & - & - \\
\hline \multicolumn{7}{|c|}{ Hemodynamic grades } \\
\hline Hirsch & - & $\begin{array}{l}\text { No spontaneous } \\
\text { venous reflux but } \\
\text { inducible reflux } \\
\text { with Valsalva } \\
\text { maneuver }\end{array}$ & $\begin{array}{l}\text { Intermittent spontaneous } \\
\text { venous reflux }\end{array}$ & $\begin{array}{l}\text { Continuous } \\
\text { spontaneous venous } \\
\text { reflux }\end{array}$ & - & - \\
\hline
\end{tabular}

of physicians is likely to ensure their inclusion in future guidelines.

Hemodynamic assessment of the varicocele by CDUS should be performed using high frequency linear probes and devices able to evaluate blood flux. To obtain accurate measurements of flux, CDUS must be calibrated to enhance slow flow. The patient is evaluated by performing the Valsalva maneuver in the supine position. A prolonged retrograde venous flow of more than $2 \mathrm{~s}$, usually evidenced by a venous rush during the Valsalva maneuver, suggests the presence of varicocele.

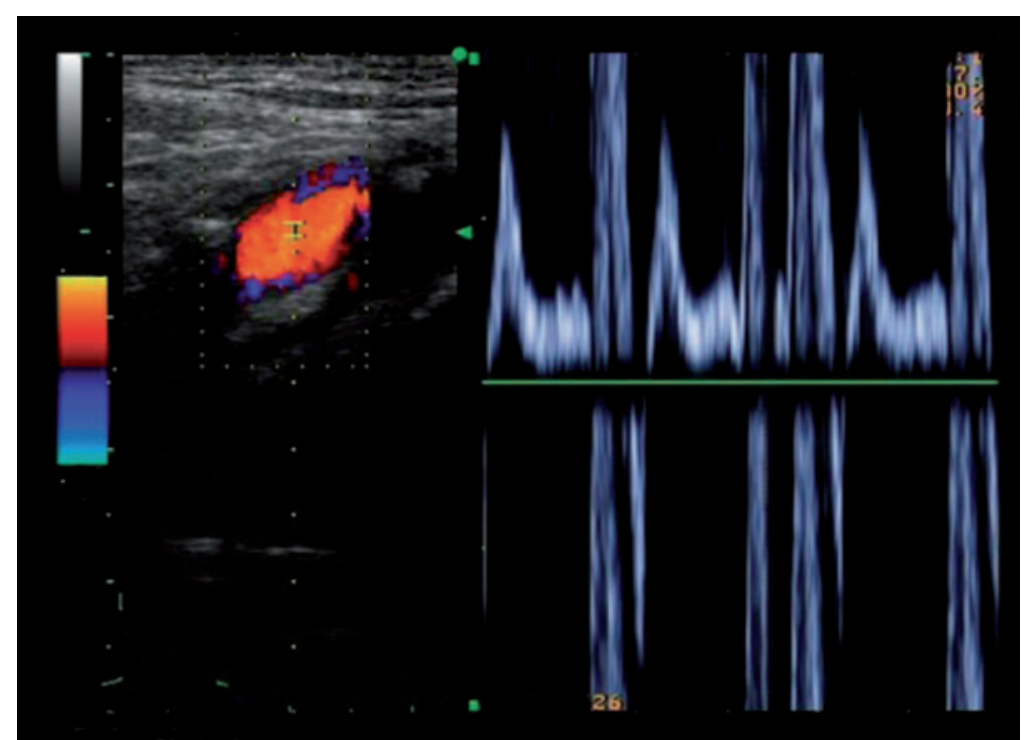

Figure 3 | The iliac artery is used as a landmark for correctly positioning the CDUS probe when exploring the iliac network. On the left-hand side, the artery appears in red as a result of blood flowing towards the probe. Small areas of blood flow turbulence near the arterial wall appear as blue. On the right-hand side, spectral analysis shows the peculiar trace of arterial blood flow with high velocity peaks during cardiac systoles and retrograde flow under the baseline during cardiac diastoles.

\section{Coolsaet type determination}

The ISV can be visualised by inserting the CDUS probe along the inguinal canal. The probe is then moved medially-ensuring that it remains along the longitudinal axis of the iliac vessels-and positioned just above the pubic tubercle. Upon locating the left iliac fossa, the deferential vein is identifiable as an arch over the external iliac vessels that runs from the internal inguinal orifice down the pelvis, joining the internal iliac vein to the vesical vein. The probe is in the correct position when the iliac artery flow is shown in red (the flow is moving towards the CDUS probe) and the iliac vein flow is shown in blue (the flow is moving away from the probe). The left external iliac artery is used as a landmark for the correct positioning of the probe (Figure 3).

In adolescent males without varicocele, the deferential vein is not visible on CDUS either at rest or during a Valsalva maneuver. When reflux is evident in the ISV (detected in the inguinal canal), but not in the deferential vein, this indicates a Coolsaet type 1 varicocele. The deferential vein only becomes visible when it is dilated and consequently refluxing. This is depicted by a change on the CDUS image from blue (normal venous flow) to red (refluxing flow). At rest, the deferential vein appears blue on the CDUS image and its trace depicts normal 'negative' flow (Figure 4a). The trace is visible under the baseline and the flow is described as 'negative' because blood is moving away from the probe.

When induced by the Valsalva maneuver, the deferential vein enters the refluxing phase and changes to red on the CDUS image (Figure 4b). The trace of its flow is inverted, such that is appears above the baseline, and the blood flow is described as 'positive' because it moves towards the probe. Upon cessation of the Valsalva maneuver, the deferential vein stops refluxing, its CDUS image color returns to blue, and its flow trace returns to below the baseline (Figure $4 \mathrm{c}-\mathrm{d}$ ). When the ISV and 
Figure 4 | CDUS screen shots and spectral analysis to show the changes that occur to the deferential vein during reflux. a Normal appearance of the deferential vein on CDUS. The vein is blue and the flow trace is under the baseline. b | The deferential vein in the refluxing phase, with the CDUS image changing from blue (normal venous flow) to red (refluxing flow). On the right-hand side, the Doppler trace clearly shows the inversion of venous flow (to above the baseline). $\mathbf{c}, \mathbf{d} \mid$ The cessation of reflux in the deferential reflux. The refluxing deferential vein (shown in red) runs from the internal inguinal orifice down the pelvis and joins the internal iliac vein to the vesical veins.

Spectral analysis shows the inverted flow above the baseline (c). The deferential vein stops refluxing upon return to rest; its color changes back to blue and the trace flow returns to below the baseline (d).

deferential vein are both visible and refluxing, it can be concluded that there is an associated reflux (Coolsaet type 3 varicocele).

\section{Hemodynamic grading systems}

Hemodynamic grading systems have been developed for adult patients, based on the principle that the longer the duration of reflux, the more severe the varicocele. Reflux types can be grouped according to the Hirsch ${ }^{34}$ classification, which distinguishes between spontaneous (intermittent or continuous) and inducible (by the Valsalva maneuver) venous refluxes (Table 1). In a grading system originally proposed by Sarteschi ${ }^{35}$ and later confirmed by Liguori, ${ }^{31}$ varicocele can be further classified into five grades according to the features, location, duration, and inducibility of the reflux (Table 1; Figures 5-8).

In adults, an inverse correlation has been established between the hemodynamic grade of reflux and the likelihood of postoperative improvement in semen parameters. ${ }^{23}$ In particular, patients with grade 1 or 2 reflux (Figure 5) according to Sarteschi's classification have been associated with significantly reduced improvement in sperm concentration $(P=0.013)$, motility $(P=0.015)$, and morphology $(P=0.45)$ compared to patients with grade 3-5 (Figures 6-8) reflux. An inducible (upon performing the Valsalva maneuver) reversal of venous flow was strongly associated with improvements in postoperative semen analysis parameters, including a $200 \%$ increase in sperm count and a 55\% increase in sperm motility. ${ }^{30}$

One study has focused specifically on the correlation between hemodynamic grade and pubertal development, testicular vein reflux, and semen quality in adolescent patients. ${ }^{36}$ All patients who developed hypotrophy and testicular asymmetry during follow-up in this study had spontaneous venous reflux on CDUS that was classified as high hemodynamic grade.

\section{Peak retrograde flow measurements}

Peak retrograde flow (PRF), which is the highest peak reached by the Doppler wave in centimeters per second, has been studied extensively in adults. A study involving 145 healthy adult men found that the average MVD and PRF values for the spermatic cord were $2.62 \mathrm{~mm}$
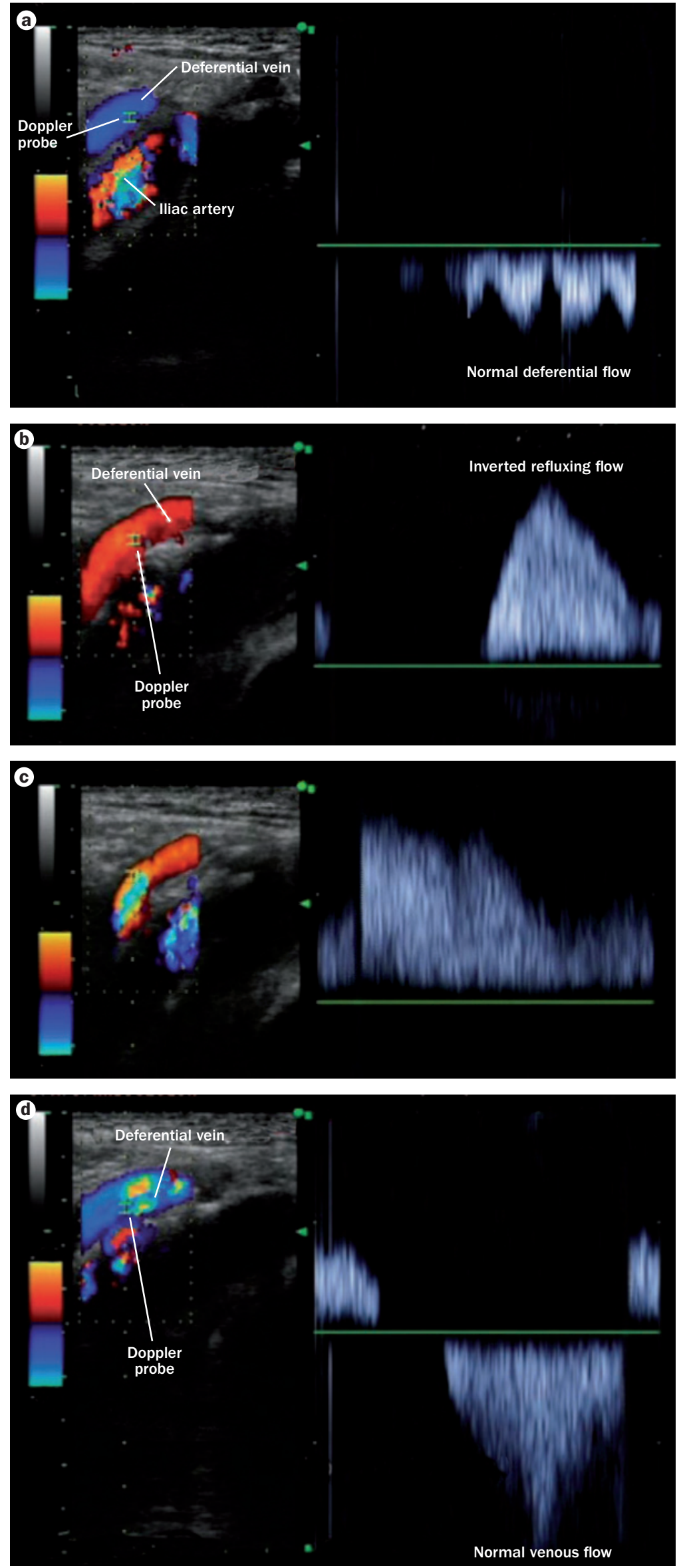

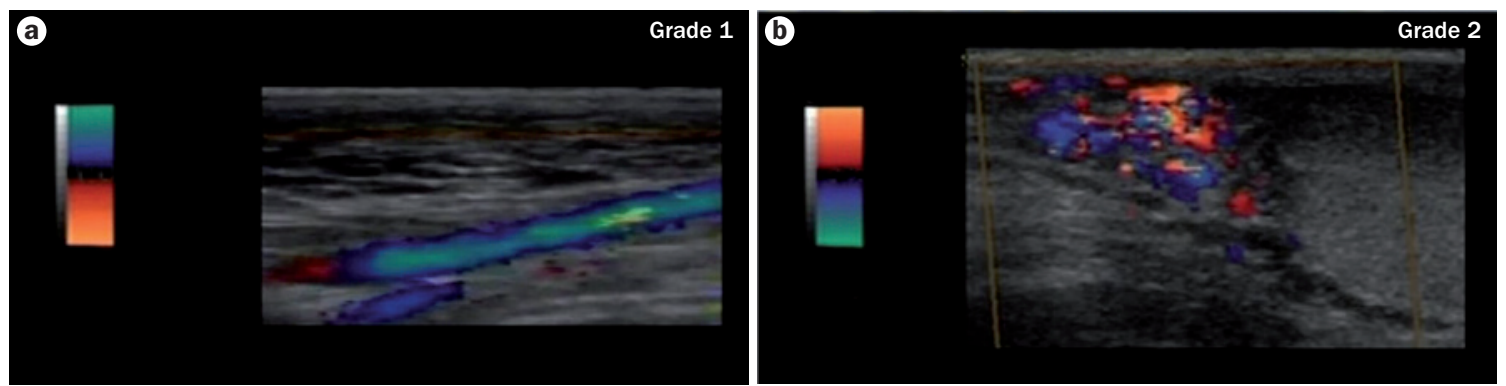

Figure 5 | CDUS image screen shots that show the hemodynamic appearance of Sarteschi grade 1 and Sarteschi grade 2 reflux. a The refluxing internal spermatic vein is detected along the inguinal canal. b | The CDUS evaluation clearly demonstrates the presence of a grade 2 venous reflux in the supratesticular region only during the Valsalva maneuver.

$( \pm 0.53 \mathrm{~mm})$ and $9 \mathrm{~cm}( \pm 7 \mathrm{~cm})$ per second, respectively, compared with $2.33 \mathrm{~mm}( \pm 0.56 \mathrm{~mm})$ and $11 \mathrm{~cm}( \pm 18 \mathrm{~cm})$ per second, respectively, in the peritesticular veins. The authors concluded that a scrotal diameter of up to $3.7 \mathrm{~mm}$ and a reflux lasting up to $3 \mathrm{~s}$ (with a velocity of $1 \mathrm{~cm}$ per second) are also evident in healthy individuals and are not definitive signs of subclinical varicocele. ${ }^{37}$ In a separate study of 154 men with left-sided varicocele, duplex Doppler ultrasonography revealed a linear relationship between PRF and MVD, and inverse correlations between both of these measurements and sperm count, mobility, and instability. A PRF of more than $40 \mathrm{~cm}$ per second was associated with abnormalities for all three semen parameters. ${ }^{38}$

In adolescent patients, a link between PRF and testicular damage has also been established. Kozakowski et al. ${ }^{24}$ observed a significantly higher mean PRF in adolescent patients with progressive testicular asymmetry (38.4 cm per second) compared to patients without progressive asymmetry $(30.4 \mathrm{~cm}$ per second; $P<0.05)$. PRF was also identified as a significant factor $(P<0.05)$ when comparing patients with new-onset asymmetry to those with decreased asymmetry. Importantly, none of the 14 patients with $>20 \%$ asymmetry and a PRF above $38 \mathrm{~cm}$ per second demonstrated an improvement in testicular asymmetry to less than $20 \%$ during follow-up, suggesting that patients presenting with both of these characteristics should be considered for immediate surgery. Findings from this study also indicated that patients with a PRF of $<30 \mathrm{~cm}$ per second should be monitored with an ultrasound and clinical examination annually or every other year. PRF values between 30 and $38 \mathrm{~cm}$ per second should alert the physician to the likelihood of persistent or new onset asymmetry. In a subsequent study, the same group confirmed these threshold values in a larger series of 115 patients with longer follow-up..$^{39}$ In this larger cohort, 95\% of patients with $\geq 20 \%$ asymmetry and a PRF of $\geq 38 \mathrm{~cm}$ per second at initial presentation had persistent $\geq 20 \%$ asymmetry at follow-up. This observation occurred independently of all other variables (including the Tanner stage) reported at initial presentation.

\section{Surgical therapy}

\section{Selecting surgical candidates}

At present, only adolescent patients with a visible or palpable dilatation of scrotal veins associated with scrotal pain or discomfort are likely to undergo surgery. As fertility testing is not routine for patients within this age group, a persistent reduction in size $(>20 \%)$ of the testicle ipsilateral to the varicocele is considered to be the main indication for surgery. Testicular ultrasound is the most accurate and reproducible method used to assess testicular volume and significant testicular size variations. However, a volume difference of less than $2 \mathrm{ml}$ can result from the measurement technique alone. Thus, a size variation of more than $2 \mathrm{ml}$ by ultrasound is currently the best indicator of testicular damage and should serve as the minimal requirement for surgical repair of the adolescent varicocele. ${ }^{15}$

As testicular disproportion might be a physiological phenomenon that occurs during normal pubertal growth, a single measurement should not be considered a definitive indication for surgery. ${ }^{40-42}$ In one study, spontaneous catch-up growth was observed in $71 \%$ of patients with $>15 \%$ initial asymmetry after a mean follow-up period of 3 years without surgery. ${ }^{41}$ In a separate study, spontaneous catch-up growth was noted in about 50\% of patients with an initial volume differential of $>20 \% .^{40}$ Thus, if testicular size is used as the only indication for surgery, a period of observation after the first detection of asymmetry is required before recommending treatment. One team of researchers have recommended that varicocelectomy be considered in adolescent patients only when $\geq 20 \%$ asymmetry has persisted for more than 1 year. $^{43}$

Guidelines suggest that adolescent patients with a varicocele but normal ipsilateral testicular size should be monitored with yearly measurements of either testicular size or semen analyses (or both). ${ }^{44,45}$ However, it is unknown whether this generic recommendation is adequate for all patients and guidance is lacking regarding the recommended duration of follow-up. Criteria for better risk stratification are needed for these patients.

\section{Fertility considerations}

The prevalence of varicocele is approximately $40 \%$ in men being evaluated for infertility. ${ }^{46,47}$ Although the presence of varicocele is considered to be one of the main correctable causes of male infertility, only $60 \%$ of adult patients with a detectable varicocele and an abnormal semen analysis will show improvement in semen parameters after varicocelectomy ${ }^{48}$ and only about $50 \%$ 
of men will ultimately father a child. ${ }^{49,50}$ By contrast, one study assessing paternity in 43 young adults who have undergone adolescent varicocelectomy found that $100 \%$ of the 18 patients who attempted to father a child were successful. This suggests either that a varicocele is just one of the factors that contribute towards infertility, that varicoceles cause progressive testicular damage if left untreated, that repair in adulthood is ineffective for restoring normal testicular function, or that a combination of these factors is responsible. Detection of varicocele in the pubertal period might, therefore, improve the efficacy of intervention. ${ }^{51}$

The argument against offering treatment to all adolescent patients on the basis of fertility alone is that only a proportion of patients will develop fertility problems later on in life. ${ }^{15}$ In addition, fertility testing is not routine in adolescents and no generally accepted standards exist to define normal semen parameters for patients in this age group. ${ }^{51}$ Although several indirect markers of testicular damage have been investigated-including inhibin $\mathrm{B},{ }^{52}$ hyperresponse to gonadotropin-releasing hormone stimulation, ${ }^{53,54}$ cytokines, ${ }^{55}$ Fas and Fas-ligand proteins, ${ }^{56}$ and reactive oxygen species antioxidants ${ }^{57}$-none reliably predict impaired testicular function in adolescents. ${ }^{53}$

\section{Pain without hypotrophy}

It is now accepted that the treatment of varicocele in children and adolescents should be concomitant with the onset of ipsilateral testicular hypotrophy (or testicular growth arrest) and pain. However, the need to treat varicocele in pediatric patients with painful varicocele but no evidence of hypotrophy is questionable. Testicular hypotrophy and semen quality are objective indicators of varicocele-related damage that can be easily measured using testicular diameter and volume (for hypotrophy) and the WHO criteria for normal semen analysis (for changes in semen quality). Pain, on the other hand, is still considered to be largely subjective, despite the use of validated questionnaires. Clinicians understand that it is not possible to assess pain with absolute certainty, especially in children, and this issue often affects the decision to treat, as well as patient randomization and data reproducibility in the context of trials.

Patients often perceive or interpret pain differently depending upon the situation they are in. Many patients with varicocele report acute pain after physical activities, such as cycling and playing football, and after long periods of standing (for example, after school). Some studies, although limited in number, have reported relief of pain after varicocelectomy. However, none of these studies have been able to explain exactly how varicoceles cause pain or why varicocelectomy should relieve it. ${ }^{58-62}$

A survey of pediatric and adolescent patients set out to assess the experience of surgery for painful varicocele. ${ }^{63}$ Patients could define their pain as either type 1 (a continuous pain sometimes treated with analgesics) or type 2 (a sense of obstruction or discomfort). Scrotal pain was reported in $11 \%$ of boys who underwent varicocelectomy, with 26 patients $(68 \%)$ describing their pain as type 1 and 12 patients (32\%) reporting type 2
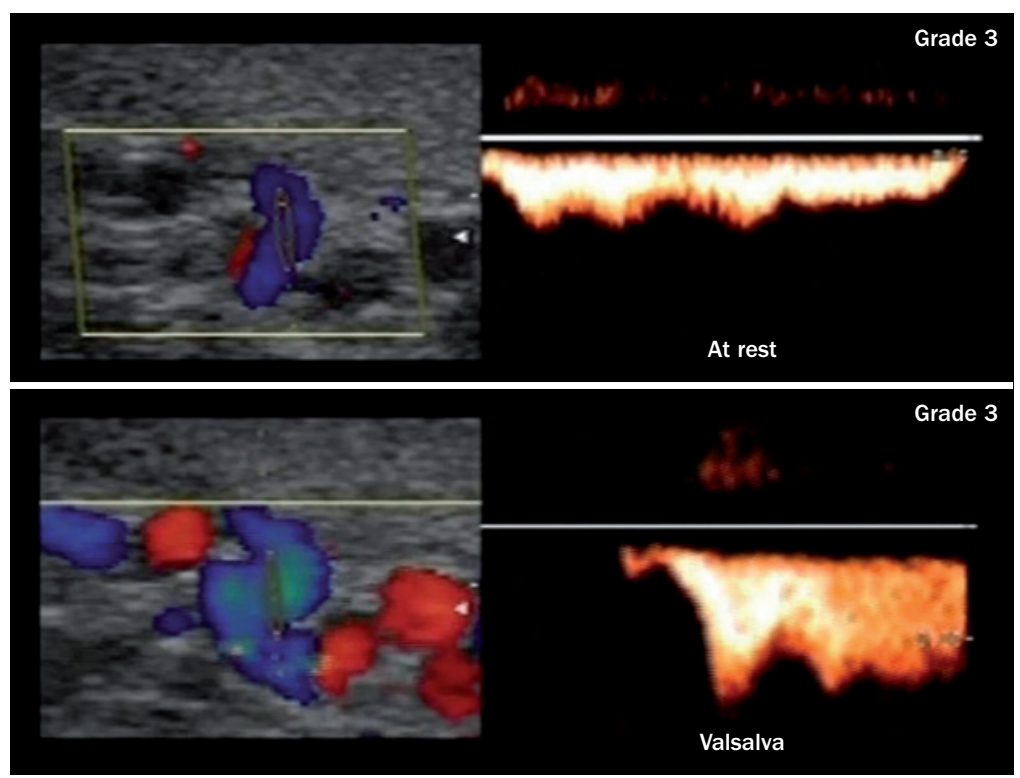

Figure 6 | CDUS image screen shot showing the hemodynamic appearance of Sarteschi grade 3 reflux. On the left-hand side, CDUS demonstrates a clear reflux only during the Valsalva maneuver. On the right-hand side, spectral analysis of venous flow shows an increase in reflux during the Valsalva maneuver.

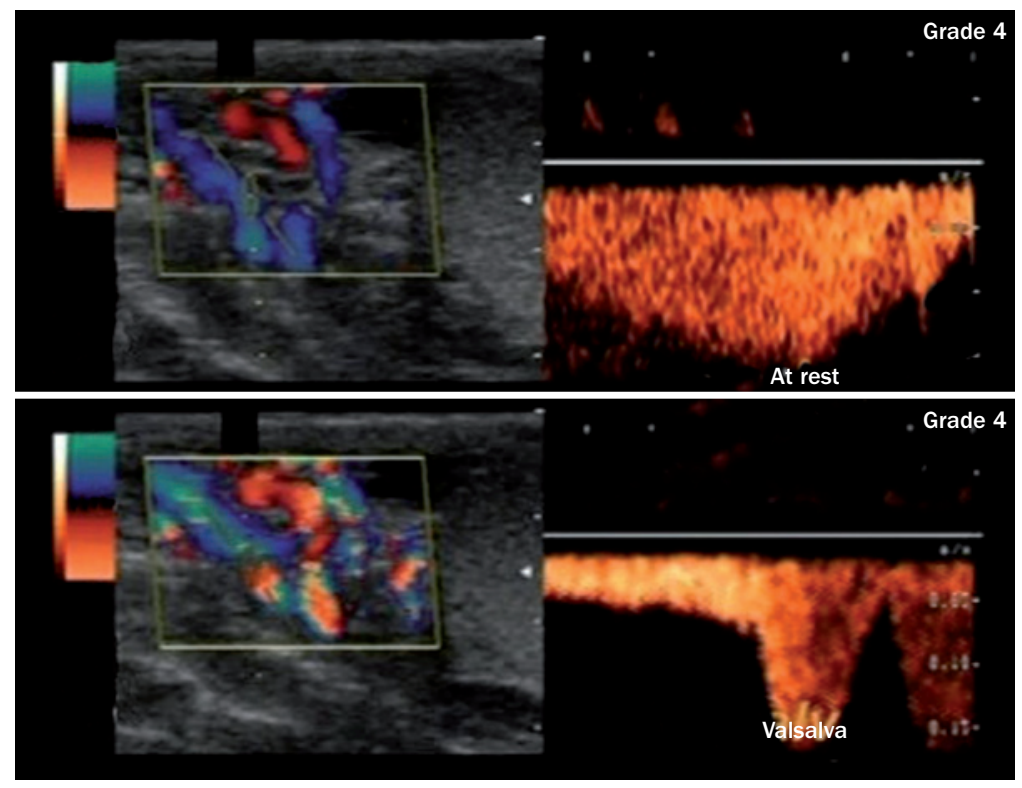

Figure 7 | CDUS screen shots and spectral analysis of Sarteschi grade 4 reflux. On the left-hand side, reflux is visible on CDUS both at rest and enhanced by the Valsalva maneuver. On the right-hand side, the same reflux is also visible with spectral analysis, which shows the prompt increase of refluxing flow during the Valsalva maneuver.

pain. 6 months after treatment, pain had resolved in 22 patients $(85 \%)$ with type 1 pain and in four patients (33.33\%) with type 2 pain. The remaining four patients with type 1 pain reported less pain but a constant scrotal discomfort, whereas all of the remaining eight patients from the type 2 group experienced no change in level of pain. There was a statistically significant correlation between preoperative pain and postoperative pain reduction $(P<0.05)$. 

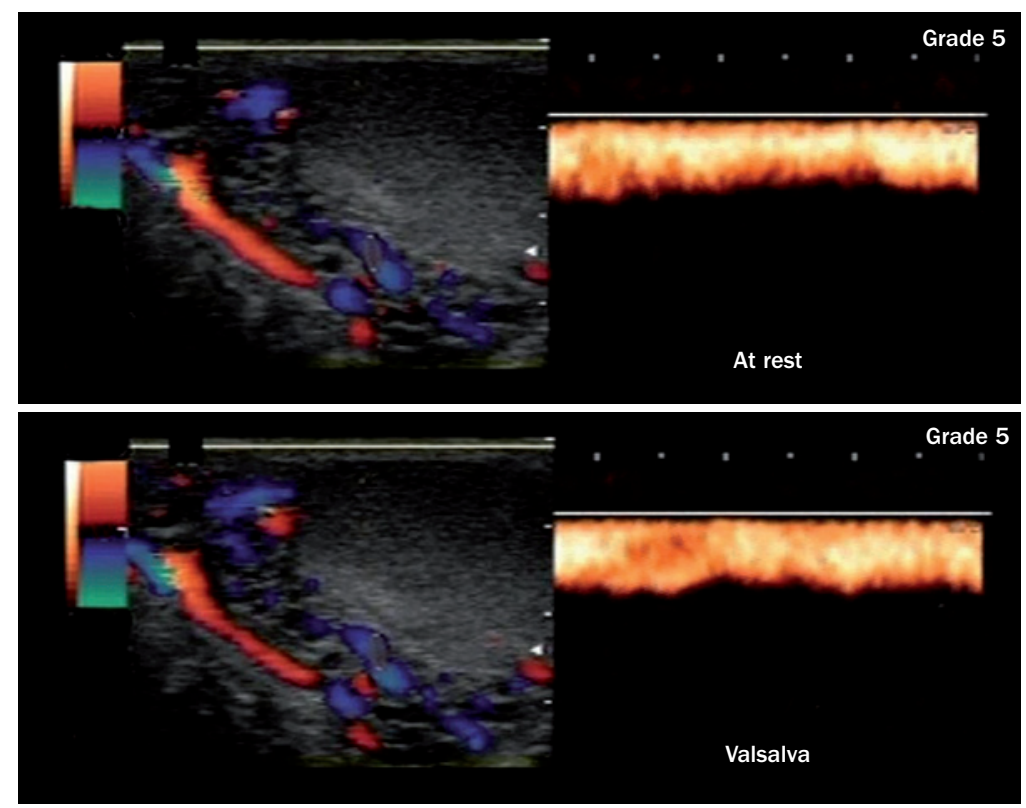

Figure 8 | CDUS screen shots and spectral analysis of Sarteschi grade 5 reflux. Venous reflux is evident at rest in both standing and supine positions. On the lefthand side, CDUS shows that persistent reflux is evident at rest and is not influenced by the Valsalva maneuver. On the right-hand side, spectral analysis shows the same. clinical varicocele, occurring with left-sided, but not bilateral, subclinical varicoceles. In a study at Children's Hospital, Boston, it was noted that right-sided subclinical varicoceles did not progress to clinically apparent lesions, whereas left-sided subclinical varicoceles progressed in $27 \%$ of patients, justifying careful observation in these patients. ${ }^{70}$

At present, the limited available evidence indicates no benefit for treatment of subclinical varicocele. No improvement in pregnancy rates was established following the repair of left subclinical varicoceles in three randomized controlled trials, ${ }^{71-73}$ and subsequent studies have demonstrated that not all subclinical varicocele repairs are associated with improved spermatogenesis. ${ }^{74}$ However, more evidence is required to make conclusive recommendations regarding repair of subclinical varicocele. ${ }^{75}$

\section{Surgical treatment options}

Effective treatment of varicocele should involve interruption of all the refluxing vessels. The ideal treatment would be effective for any type of varicocele, have minimal morbidity, preserve optimal testicular function, and be cost effective. ${ }^{76}$ Postoperative varicocele persistence rate represents the most practical objective outcome measure to compare the various techniques that are currently available, including microsurgical subinguinal varicocelectomy, radiological embolization, and laparoscopic varicocelectomy.

In principle, open subinguinal microsurgical varicocelectomy-which simultaneously exposes all three major venous systems forming the pampiniform plexus - should be the most flexible and effective approach. Additionally, use of the operating microscope and intraoperative Doppler ultrasonography should enable an artery-sparing and lymphatic-sparing varicocelectomy. Varicocele persistence rates as low as $0 \%$ have been reported using this technique. ${ }^{77}$ However, a major drawback of this approach is the need for microsurgical skills and, in our own experience, persistence rates of about $3.2 \%$ are more realistic. ${ }^{78}$

Radiological treatment can be performed in either a retrograde or antegrade fashion. The former is associated with a $10-15 \%$ rate of technical failure in children, making it impractical for clinical use. ${ }^{79}$ One drawback of antegrade sclerotherapy is that it requires a combination of specialist surgical skills (to dissect a vein in the scrotum for cannulation) and specialist radiological equipment. Persistence rates range from $7 \%$ to $20 \%$, possibly because this surgical approach only addresses reflux in the ISV. ${ }^{79-82}$

Laparoscopic and retroperitoneoscopic varicocelectomy have also gained popularity in the last decade. Irrespective of the approach, a Palomo high ligature of the ISV is performed, which means that refluxes in associated districts are not addressed. ${ }^{16}$ In recent years, a laparoscopic approach has been preferred. This change in strategy over the last decade follows the introduction of CDUS into the preoperative work-up of patients with varicocele. Initially, a laparoscopic varicocelectomy 
was only elected in patients for whom preoperative CDUS showed reflux in the ISV alone. For all other patients, a subinguinal approach was recommended. ${ }^{9}$ Subsequently, a modified laparoscopic technique was developed that was also able to address reflux in the deferential vein shown by CDUS (Figure 9).$^{6-8}$ Using this approach, surgeons have managed to progressively lower persistence rates.

Surgical approach can be selected on the basis of preoperative CDUS results. In a recent study of 98 adolescent patients with varicoceles, CDUS showed reflux in the ISV only in 87 patients $(88.7 \%)$ and a reflux in both the ISV and the deferential vein in the remaining 11 patients (11.2\%). ${ }^{6}$ A laparoscopic Palomo procedure was performed for all patients, but the 11 patients with reflux in the deferential vein also underwent coagulation and section of this vein. In two patients, the deferential vein was approached in the deep pelvis because of evident dilation of the vein. After a median follow-up period of 18 months (6-49 month range), three patients (4.2\%) developed postoperative hydrocele (all of which resolved spontaneously). None of the patients experienced varicocele recurrence, detected clinically or by CDUS scanning. No cases of testicular atrophy were observed. Median left testicular volume increased significantly after surgery $(P=0.025)$ in patients presenting with hypotrophy of the left testicle. ${ }^{6}$

Other studies have added to these findings. Nagar and Mabjeesh ${ }^{83}$ recommend high ligation in cases where CDUS demonstrates reverse flow on Valsalva maneuver and a low ligation if reverse flow is not demonstrable. This guidance is based on the assumption that the ISV is the principal drainage path for the scrotal vein when a reverse flow on Valsalva maneuver is observed. Using this approach, they reported a persistence rate of 3.8\% after a follow-up of 18 months, which was significantly lower than previously observed rates $(20.5 \% ; P=0.004)$.

Dudai et al. ${ }^{84}$ described a modified laparoscopic procedure that includes a systematic interruption of both the ISV and the inferior epigastric vessels. Although the principle is similar to other techniques, this approach differs in that it is systematic and, therefore, increases the risk of overtreatment. Furthermore, interruption of the inferior epigastric vessels addresses only a possible cremasteric reflux, which has a questionable role in the onset of varicocele..$^{5,6}$

It should be noted that the effect of pelvic refluxing collateral veins on varicocele persistence remains controversial. A large randomized controlled trial might address this issue, but its setup would be impractical for ethical reasons. Indirect evidence suggests that, in a few cases, varicocele persistence can be caused by pelvic refluxing collaterals. ${ }^{3,485}$ However, in a study of repeat varicocelectomies, Glassberg et al. ${ }^{86}$ noted that distal collaterals did not generally cause recurrences and these veins were left intact in all but one patient. Consistent with these findings, promising results have been reported for the use of antegrade sclerotherapy in reinterventional varicocelecetomies, despite the fact that these techniques address only a reflux in the ISV. ${ }^{81}$
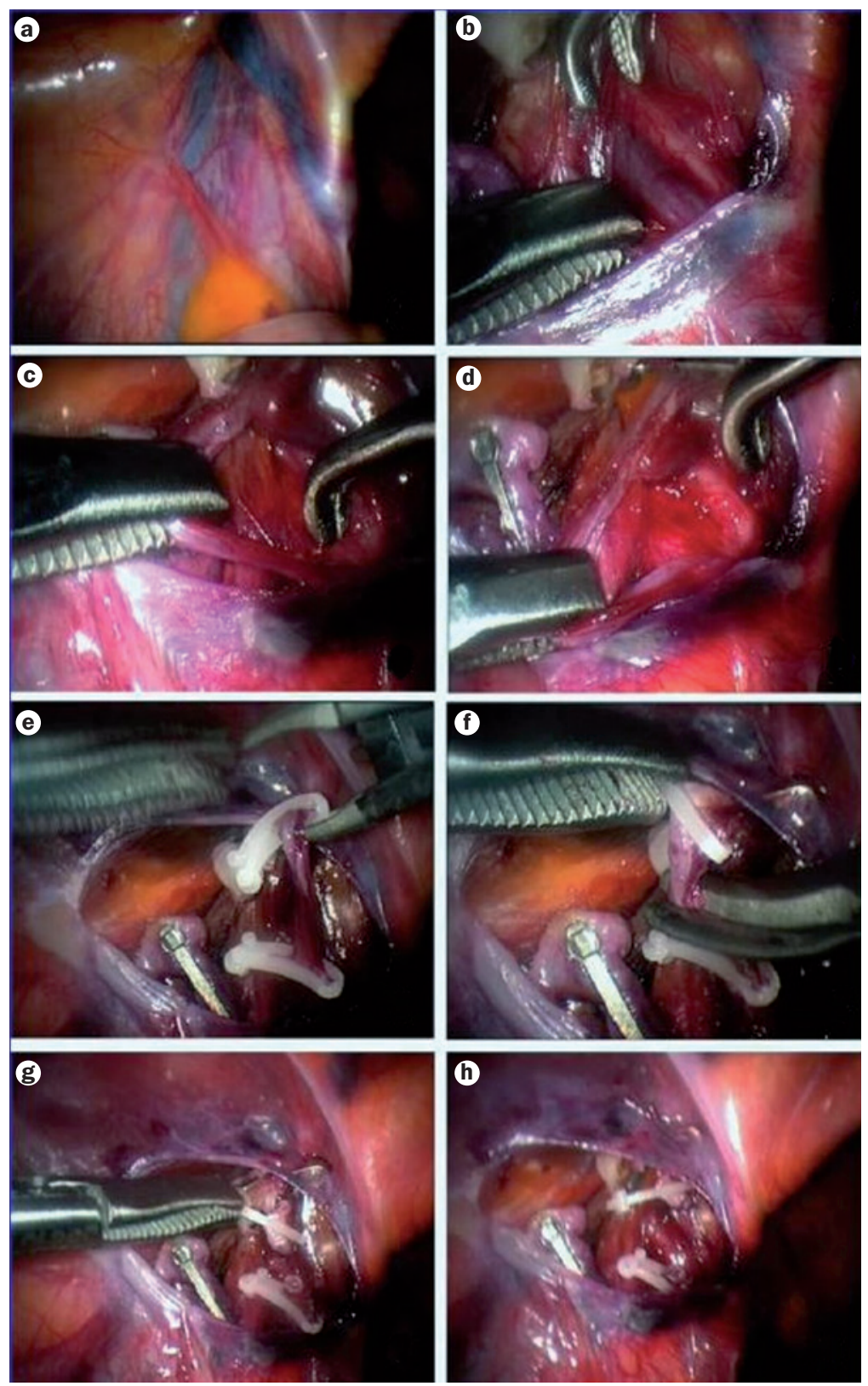

Figure 9 | Laparoscopic approach to varicocele repair in the deferential vein. $\mathbf{a , b} \mid$ The dilated deferential vein is easily detectable from the laparoscopic view. c,d $\mid$ The deferential vein is visible at a considerable distance from the vas deferens. e-h | Division of the deferential vein after clipping.

\section{Postoperative follow-up}

The major outcome measure used to assess the success of varicocelectomy is testicular volume. Surgical intervention reverses testicular growth arrest, and postoperative assessment of testicular volume predicts resolution of the varicocele. ${ }^{87,88}$ Postoperative catch-up growth is reported to occur in $60-80 \%$ of patients undergoing varicocelectomy, irrespective of age or Tanner stage at surgery. ${ }^{89-91}$

Studies of CDUS use in the postoperative follow-up of patients undergoing varicocelectomy are extremely sparse. Sun et al. ${ }^{92}$ investigated postoperative CDUS use, but with the main purpose of showing that testicular blood supply is preserved after ligation of the spermatic 
artery. Glassberg et al. ${ }^{86}$ identified high PRF as a potential indication for repeat varicocelectomy in patients with preserved testicular asymmetry, but did not provide substantive evidence to support this theory. As no data are currently available on the use of CDUS for the detection of persistent subclinical varicocele, it seems unwarranted to consider repeat procedures based upon this indication.

\section{Conclusions}

According to the best available evidence, persistent reduced testicular volume should be considered the main indication for varicocelectomy in adolescent patients. Clinical grading is important to stratify patients, but it correlates poorly with the risk of developing testicular asymmetry. Hemodynamic parameters have shown promise in identifying patients at risk of having persistent or worsening asymmetry on follow-up. Although further studies are necessary to validate single parameters, it is apparent that the more severe the reflux, the higher the likelihood that the patient will develop testicular asymmetry during follow-up. A continuous retrograde flow or a PRF above $38 \mathrm{~cm}$ per second indicate the presence of severe varicocele. According to one study, patients with more than $20 \%$ asymmetry and a PRF above $38 \mathrm{~cm}$ per second should undergo immediate surgical repair. For surgical candidates, Doppler ultrasonography might help in the selection of the most effective surgical approach. In particular, it could enable the identification of a reflux in the deferential vein associated with reflux in the ISV, which could cause varicocele persistence if left untreated.

\section{Review criteria}

We searched for original research articles on varicocele in MEDLINE and PubMed published between 1990 and 2012. The search terms we used were "varicocele", "humans", and "age: adolescent: 13-18 years". We also searched the reference lists of identified articles for additional pertinent papers.
1. Dubin, L. \& Amelar, R. D. Varicocele size and results of varicocelectomy in selected subfertile men with varicocele. Fertil. Steril. 21, 606-609 (1970).

2. Coolsaet, B. L. The varicocele syndrome: venography determining the optimal level for surgical management. J. Urol. 124, 8338-8339 (1980).

3. Niedzielski, J. \& Paduch, D. A. Recurrence of varicocele after high retroperitoneal repair: implications of intraoperative venography. J. Urol. 165, 927-929 (2001).

4. Campobasso, P. Blue venography in adolescent varicocelectomy: a modified surgical approach. J. Pediatr. Surg. 32, 1298-1301 (1997).

5. Franco, G. et al. Challenging the role of cremasteric reflux in the pathogenesis of varicocele using a new venographic approach. J. Urol. 161, 117-121 (1999).

6. Cimador, M. et al. Comprehensive laparoscopic approach to pediatric varicocele based on preoperative color Doppler ultrasound assessment. Surg. Endosc. 22, 701-705 (2008).

7. Castagnetti, M. et al. Evolving management of adolescent varicocele. J. Pediatr. Urol. 4, 107-112 (2008).

8. Cimador, M. et al. Laparoscopic surgery of deferential reflux in pediatric and adolescent varicocele. J. Laparoendosc. Adv. Surg. Tech. 19, S133-S136 (2009).

9. Cimador, M. et al. The role of Doppler ultrasonography in determining the proper surgical approach to the management of varicocele in children and adolescents. BJU Int. 97, 1291-1297 (2006).

10. Paduch, D. A. \& Skoog, S. J. Current management of adolescent varicocele. Rev. Urol. 3, 120-133 (2001).

11. Diamond, D. A. et al. Relationship of varicocele grade and testicular hypotrophy to semen parameters in adolescents. J. Urol. 178, 1584-1588 (2007).

12. Gershbein, A. B., Horowitz, M. \& Glassberg, K. I. The adolescent varicocele I: left testicular hypertrophy following varicocelectomy. J. Urol. 162, 1447-1449 (1999).

13. Kass, E. J. \& Belman, A. B. Reversal of testicular growth failure by varicocele ligation. J. Urol. 137, 475-476 (1987).
14. Costabile, R. A., Skoog, S. \& Radowich, M. Testicular volume assessment in the adolescent with a varicocele. J. Urol. 147, 1348-1350 (1992).

15. Skoog, S. J. et al. The adolescent varicocele: what's new with an old problem in young patients? Pediatrics 100, 112-122 (1997).

16. Schiff, J. D., Li, P. S. \& Goldstein, M. Correlation of ultrasonographic and orchidometer measurements of testis volume in adults. BJU Int. 93, 1015-1017 (2004).

17. Sakamoto, H., Saito, K., Ogawa, Y. \& Yoshida, H. Testicular volume measurements using Prader orchidometer versus ultrasonography in patients with infertility. Urology 69, 158-162 (2007).

18. Diamond, D. A. et al. Comparative assessment of pediatric testicular volume: orchidometer versus ultrasound. J. Urol. 164, 1111-1114 (2000).

19. Sakamoto, H. et al. Testicular volume measurement: comparison of ultrasonography, orchidometry, and water displacement. Urology 69, 152-157 (2007).

20. Rowe, P. J., Comhaire, F. H., Hargreave, T. B. \& Mahmoud, A. M. A. WHO manual for the standardized investigation, diagnosis and management of the infertile male. (Cambridge University Press, Cambridge, 2000).

21. Thomas, J. C. \& Elder, J. S. Testicular growth arrest and adolescent varicocele: does varicocele size make a difference? J. Urol. 168, 1689-1691 (2002).

22. Alukal, J. P. et al. Testicular hypotrophy does not correlate with grade of adolescent varicocele. J. Urol. 174, 2367-2370 (2005).

23. Hussein, A. F. The role of color Doppler ultrasound in prediction of the outcome of microsurgical subinguinal varicocelectomy. J. Urol. 176, 2141-2145 (2006).

24. Kozakowski, K. A. et al. Peak retrograde flow: a novel predictor of persistent, progressive and new onset asymmetry in adolescent varicocele. J. Urol. 181, 2717-2722 (2009).

25. Kocakoc, E. et al. Color Doppler sonographic evaluation of inter-relations between diameter, reflux and flow volume of testicular veins in varicocele. Eur. J. Radiol. 47, 251-256 (2003).

26. Hoekstra, T. \& Witt, M. A. The correlation of internal spermatic vein palpability with ultrasonographic diameter and reversal of venous flow. J. Urol. 153, 82 (1995).
27. Pilatz, A., Altinkilic, B., Köhler, E., Marconi, M. \& Weidner, W. Color Doppler ultrasound imaging in varicoceles: is the venous diameter sufficient for predicting clinical and subclinical varicocele? World J. Urol. 29, 645-650 (2011).

28. Atasoy, C. \& Fitoz, S. Gray-scale and color Doppler sonographic findings in intratesticular varicocele. J. Clin. Ultrasound 29, 369-373 (2001).

29. Tanrikut, C. \& Goldstein, M. Varicocele: size does matter. J. Urol. 176, 1912-1913 (2006).

30. Schiff, J. D., Li, P. S. \& Goldstein, M. Correlation of ultrasound-measured venous size and reversal of flow with Valsalva with improvement in semen-analysis parameters after varicocelectomy. Fertil. Steril. 86, 250-252 (2006).

31. Liguori, G. et al. Color Doppler ultrasound investigation of varicocele. World J. Urol. 22, 378-381 (2004).

32. Paduch, D. A. \& Niedzielski, J. Semen analysis in young men with varicocele: preliminary study. J. Urol. 156, 788-790 (1996).

33. Tekgul, S. et al. EAU-ESPU guidelines on paediatric urology (page 23). http://www. uroweb.org/gls/pdf/19_Paediatric_Urology.pdf (2011).

34. Hirsh, A. V., Cameron, K. M., Tyler, J. P., Simpson, J. \& Pryor, J. P. The Doppler assessment of varicoceles and internal spermatic vein reflux in infertile men. Br. J. Urol. 52, 50 (1980).

35. Sarteschi, L. M., Paoli, R., Bianchini, M. \& Menchini Fabris, G. F. The study of varicocele with echo-color Doppler. [Lo studio del varicocele con eco-color Doppler.] G. Ital. Ultrasonol. 4, 43 (1993).

36. Zampieri, N. \& Cervellione, R. M. Varicocele in adolescents: a 6-year longitudinal and follow-up observational study. J. Urol. 180, 1653-1656 (2008).

37. Cina, A. et al. Sonographic quantitative evaluation of scrotal veins in healthy subjects: normative values and implications for the diagnosis of varicocele. Eur. Urol. 50, 345-350 (2006).

38. Gitlin, J. \& McCullough, A. Peak venous flow: a novel sonography parameter for evaluating patients with varicoceles. Presented at Ferdinand C.Valentine Resident Essay Contest 
at annual meeting of New York Academy of Medicine, New York (2001).

39. Van Batavia, J. P. et al. Adolescent varicocele: influence of Tanner stage at presentation on the presence, development, worsening and/or improvement of testicular hypotrophy without surgical intervention. J. Urol. 184, 1727-1732 (2010).

40. Preston, M. A., Carnat, T., Flood, T., Gaboury, I. \& Leonard, M. P. Conservative management of adolescent varicoceles: a retrospective review. Urology 72, 77-80 (2008).

41. Kolon, T. F. et al. Transient asynchronous testicular growth in adolescent males with a varicocele. J. Urol. 180, 1111 (2008).

42. Poon, S. A. et al. Testicular asymmetry and adolescent varicoceles managed expectantly. J. Urol. 183, 731-734 (2010).

43. Diamond, D. A. et al. Is adolescent varicocele a progressive disease process? J. Urol. 172 , 1746-1748 (2004).

44. Jarow, J. P. et al. Best practice policies for male infertility. J. Urol. 167, 2138 (2002).

45. Tekgul, S. et al. EAU-ESPU guidelines on paediatric urology: limited update (page 349) http://www.uroweb.org/gls/pockets/ english/22\%20Paediatric\%20Urology.pdf (2011).

46. Gorelick, J. I. \& Goldstein, M. Loss of fertility in men with varicocele. Fertil. Steril. 59, 613 (1993).

47. Jarow, J. P., Coburn, M. \& Sigman, M. Incidence of varicoceles in men with primary and secondary infertility. Urology 47, 73 (1996).

48. Pryor, J. L. \& Howards, S. S. Varicocele. Urol. Clin. North Am. 14, 499 (1987).

49. Shamsa, A., Nademi, M., Aqaee, M., Fard, A. N. \& Molaei, M. Complications and the effect of varicocelectomy on semen analysis, fertility, early ejaculation and spontaneous abortion. Saudi J. Kidney Dis. Transpl. 21, 1100-1105 (2010).

50. Dubin, L. \& Amelar, R. D. Varicocelectomy: 986 cases in a twelve-year study. Urology 10 , 446-449 (1977).

51. Salzhauer, E. W., Sokol, A. \& Glassberg, K. I. Paternity after adolescent varicocele. Pediatrics 114, 1631 (2004).

52. Romeo, C. et al. Altered serum inhibin b levels in adolescents with varicocele. J. Pediatr. Surg. 42 390-394 (2007).

53. Fideleff, H. L. et al. Controversies in the evolution of paediatric-adolescent varicocele: clinical, biochemical and histological studies. Eur. J. Endocrinol. 143, 775-781 (2000).

54. Guarino, N., Tadini, B. \& Bianchi, M. The adolescent varicocele: the crucial role of hormonal tests in selecting patients with testicular dysfunction. J. Pediatr. Surg. $\mathbf{3 8}$ 120-123 (2003).

55. Matalliotakis, I. et al. Distinct expression pattern of cytokines in semen of men with genital infection and oligo-terato-asthenozoospermia. Am. J. Reprod. Immunol. 48, 170-175 (2002).

56. Fujisawa, M. \& Ishikawa, T. Soluble forms of Fas and Fas ligand concentrations in the seminal plasma of infertile men with varicocele. J. Urol. 170, 2363-2365 (2003).

57. Mostafa, T., Anis, T., El Nashar, A., Imam, H. \& Osman, I. Seminal plasma reactive oxygen species-antioxidants relationship with varicocele grade. Andrologia 44, 66-69 (2012).
58. Peterson, A. C., Lance, R. S. \& Ruiz, H. E. Outcomes of varicocele ligation done for pain. J. Urol. 159, 1565-1567 (1998).

59. Yeniyol, C. O., Tuna, A., Yener, H., Zeyrek, N. \& Tilki, A. High ligation to treat pain in varicocele. Int. Urol. Nephrol. 35, 65-68 (2003).

60. Maghraby, H. A. Laparoscopic varicocelectomy for painful varicoceles: merits and outcomes. J. Endourol. 16, 107-110 (2002).

61. Yaman, O., Ozdiler, E., Anafarta, K. \& Gogus, O. Effect of microsurgical subinguinal varicocele ligation to treat pain. Urology 55, 107-108 (2000).

62. Kim, S. O., Jung, H. \& Park, K. Outcomes of microsurgical subinguinal varicocelectomy for painful varicoceles. J. Androl. doi:10.2164/ jandrol.111.014993.

63. Zampieri, N., Ottolenghi, A. \& Camoglio, F. S. Painful varicocele in pediatric age: is there a correlation between pain, testicular damage and hormonal values to justify surgery? Pediatr. Surg. Int. 24, 1235-1238 (2008).

64. Yaman, O., Ozdiler, E., Anafarta, K. \& Gogus, O. Effect of microsurgical subinguinal varicocele ligation to treat pain. Urology 55, 107-108 (2000).

65. Karademir, K. et al. Evaluation of the role of varicocelectomy including external spermatic vein ligation in patients with scrotal pain. Int. Urol. 12, 484-488 (2005).

66. Maghraby, H. A. Laparoscopic varicocelectomy for painful varicoceles: merits and outcomes. J. Endourol. 16, 107-110 (2002).

67. Al- Buheissi, S. Z., Patel, H. R., Wazait, H. D., Miller, R. A. \& Nathan, S. Predictors of success in surgical ligation of painful varicocele. Urol. Int 79, 33-36 (2007).

68. Kocakoc, E. et al. Incidence and importance of reflux in testicular veins of healthy men evaluated with color duplex sonography. J. Clin. Ultrasound 30, 282-287 (2002).

69. Cervellione, R. M., Corroppolo, M. \& Bianchi, A. Subclinical varicocele in the pediatric age group. J. Urol. 179, 717-719 (2008).

70. Diamond, D. A., Gargollo, P. C. \& Caldamone, A. A. Current management principles for adolescent varicocele. Fertil. Steril. 96, 1294-1298 (2011).

71. Grasso, M. et al. Lowgrade left varicocele in patients over 30 years old: the effect of spermatic vein ligation on fertility. BJU Int. $\mathbf{8 5}$ 305-307 (2000).

72. Unal, D., Yeni, E., Verit, A. \& Karatas, O. F. Clomiphene citrate versus varicocelectomy in treatment of subclinical varicocele: a prospective randomized study. Int. J. Urol. 8, 227-230 (2001).

73. Yamamoto, M., Hibi, H., Hirata, Y., Miyake, K. \& Ishigaki, T. Effect of varicocelectomy on sperm parameters and pregnancy rate in patients with subclinical varicocele: a randomized prospective controlled study. J. Urol. 155, 1636-1638 (1996).

74. Jarow, J. P., Ogle, S. R. \& Eskew, L. A. Seminal improvement following repair of ultrasound detected subclinical varicocele. J. Urol. 155 , 1287-1290 (1996).

75. Baazeem, A. et al. Varicocele and male factor infertility treatment: a new meta-analysis andreview of the role of varicocele repair. Eur. Urol. 60, 796-808 (2011).

76. Goldstein, M. Adolescent varicocele. J. Urol. 153, 484-485 (1995).
77. Schiff, J., Kelly, C., Goldstein, M., Schelegel, P. \& Poppas, D. Managing varicoceles in children: results with microsurgical varicocelectomy. BJ Int. 95, 399-402 (2005)

78. Cimador, M. et al. Sub-inguinal interruption of dilated veins in adolescent varicocele: should it be considered a gold standard technique? Minerva Pediatr. 55, 599-605 (2003).

79. Beutner, S. et al. Treatment of varicocele with reference to age: a retrospective comparison of three minimally invasive procedures. Surg. Endosc. 21, 61-65 (2007).

80. Mazzoni, G. et al. Varicocele: a multidisciplinary approach in children and adolescents. J. Urol. 162, 1755-1758 (1999).

81. Galfano, A. et al. Surgical outcomes after modified antegrade scrotal sclerotherapy: a prospective analysis of 700 consecutive patients with idiopathic varicocele. J. Urol. 179, 1933-1937 (2008).

82. Zupa, P., Mayr, J. \& Hollwarth, E. Antegrade scrotal sclerotherapy for treating primary varicocele in children. BJU Int. 97, 809-812 (2006).

83. Nagar, H. \& Mabjeesh, N. J. Decision-making in pediatric varicocele surgery: use of color Doppler ultrasound. Pediatr. Surg. Int. 15, 75-76 (2000).

84. Dudai, M., Sayfan, J., Mesholam, J. \& Sperber, Y. Laparoscopic simultaneous ligation of internal and external spermatic veins for varicocele. J. Urol. 153, 704-705 (1995).

85. Esposito, C. et al. Laparoscopic treatment of pediatric varicocele: a multicenter study of the italian society of video surgery in infancy. J. Urol. 163, 1944-1946 (2000).

86. Glassberg, K. I. et al. Evaluation and management of the persistent/recurrent varicocele. Urology 77, 1194-1198 (2011).

87. Atassi, O., Kass, E. J. \& Steinert, B. W. Testicular growth after successful varicocele correction in adolescents: comparison of artery sparing techniques with the Palomo procedure. J. Urol. 153, 482-483 (1995).

88. Kass, E. J. \& Reitelman, C. Adolescent varicocele. Urol. Clin. North Am. 22, 151-159 (1995).

89. Cayan, S. et al. The effect of varicocele repair on testicular volume in children and adolescent with varicocele. J. Urol. 168 731-734 (2002)

90. Greenfield, S. P. Seville, P. \& Wan, J. Experience with varicocele in children and young adults. J. Urol. 168, 1684-1688 (2002).

91. Decastro, G. J., Shabsigh, A., Poon, S. A. Laor, L. \& Glassberg, K. I. Adolescent varicocelectomy-is the potential for catch-up growth related to age and/or Tanner stage? J. Urol. 181, 322-327 (2009).

92. Sun, N., Cheung, T. T., Kong, P. L., Chan, K. L. \& Tam, P. K. H. Varicocele: laparoscopic clipping and color Doppler follow-up. J. Pediatr. Surg. 36, 1704-1707 (2001).

\section{Author contributions}

M. Cimador, M. Castagnetti, I. Gattuccio, M. Pensabene and M. Sergio contributed towards researching the literature. M. Cimador and M. Castagnetti discussed the content and wrote the article. M. Cimador, M. Pensabene and E. DeGrazia reviewed and edited the final manuscript prior to submission. 